\title{
Research of Luxury Consumption by College Students
}

\author{
Qiwei Zhan \\ The University of Sydney, NSW 2000, Australia
}

\begin{abstract}
In recent years, China's economy has rapid development and maintained stable, and the lives of our residents have been well improved. With the growth of the income level of our residents, the consumption level has also been continuously improved, and the overall quality of life has been improved; the rich groups in China are constantly developing and expanding, and the scale of highasset net worth people is also expanding, which has become one of the reasons why more and more people pursuing luxury goods. In the consumer group that consumes luxury goods, it dominates Generation $Y$ and $Z$, becoming the main market for luxury goods consumption. Young-generation has become a new pet for luxury goods and uses traditional luxury goods as a "social status symbol, showing off identity" is gradually reversed to the concept of "own personalized enjoyment and selfworth manifestation". This article will investigate the motives and effects of university students' luxury consumption through quantitative analysis of questionnaires.
\end{abstract}

Keywords: University Students; Luxury Goods; Consumer Behaviors.

\section{Introduction}

In recent years, with the rapid development of our economy, the income level of our residents has increased. Studies have shown that the consumption level of our country has increased with the development of society in recent years. The rich class in China is growing rapidly, and the size of the high-asset net worth population is expanding year by year. According to the survey data of Hu Run Research Institute, as of 2019, the number of tens of millions of high-net-worth people in mainland China was about 1.34 million, an increase of 130,000 from the previous year. The growth rate is as high as $10.7 \%$; the number of people with high net worth is about $8.90,000$, an increase of $1.10,000$ people, the growth rate is as high as $14.1 \%$, [1] my country's middle class is rapidly rising and disposable income is increasing, and the overall trend of individual contributions to the luxury market is upward.

In recent years, the leapfrog development of the Chinese economy has made a large number of young people rich, and they have played a central role in the ranks of consumer goods. In order to show their value, most white-collar workers live a prosperous life, and they will spend a large proportion of their income on the consumption of luxury goods; in our country, the elderly will save their life savings to their children whom do not need to work hard- "The rich second generation" of wealth and" the second generation of officials" also enhance the ability of my country to consume luxury goods. In McKinsey's "The Report of Chinese Luxury 2019", the report shows that in recent years, the international economy has declined, the world's geopolitical instability, and in the context of Chinese slowing economic development, Chinese luxury market has shown no signs of weakness but continues to grow. The huge consumer market behind this growth is the young-generation represented Generation $\mathrm{Y}$ and $\mathrm{Z}$; the young-generation has become the new trend of purchasing luxury. [2] As the millennium-generation becomes a potential purchaser of luxury goods, luxury goods evolve from a symbol of identity status and a means of showing off into an expression of personality. With the development of the self-media and online-stage, and in order to attract the attention of more young people, various luxury brands have played rejuvenated marketing methods, such as using Internet-stars as endorsements, or live webcasts.

The main research subject of this article is young people, specifically referring to the luxury consumption motivation of college students, revealing the relationship between the main factors affecting their consumption of luxury goods and their willingness to purchase; they put forward suggestions and intervention measures for college students to consume luxury goods. This article first reviews through the literature to understand the theoretical research, methods and conclusions of the 
former on this topic; secondly, this article conducts quantitative analysis by distributing questionnaires online. The content of the research is the college students' consumption of luxury goods-some wishes and factors that affect their consumption; The dimensions of the questionnaire are designed to include the gender of the questionnaire, its monthly disposable amount, the source of the cost of purchasing luxury goods, and the attitude towards consumer luxury goods and the main types of luxury goods consumed and the frequency of purchases to analyze the behavior of luxury goods consumed by college students to conclude the results. Finally, this article summarizes the intervention strategies for the irrational consumption of luxury goods by college students.

The following findings have been made through literature research and empirical research: 1. Most college students buy luxury goods from the source of living expenses from their parents and working to make money. 2. Most college students consider buying luxury goods because of better quality and willingness to spend more money to consume better things; therefore, in the behavior of college students consuming luxury goods, the main motivation for consuming luxury goods is the quality of luxury brands. 3. Stars and net-populars endorsement effects have not played a large role in the market for luxury goods consumed by college students; star effects and popular psychology have less influence in the consumption of luxury goods by college students. 4. Most college students buy luxury goods for their own pleasure and use the purchase of luxury goods as a reward for their work and study; therefore, more college students use the act of buying luxury goods as a motivation for their own-kind encouragement or learning.

\section{Literature Review}

\subsection{Definition of Related Concepts}

\subsubsection{Luxury Goods}

Walgang Ratsler defined luxury in the best-selling book "Luxury brings prosperity": "Luxury is a way of living that is considered by their respective societies, mostly determined by products or services wholly or partially ". [3] It is defined internationally as "a type of consumer goods with unique, scarce, rare, and other characteristics beyond the scope of people's survival and development needs", and is also called a non-life necessity. [4] In a narrow sense, "expensive and uncommon" goods are called luxury goods. Luxury goods are divided into: various expensive artworks in the literary and artistic market; luxury goods belonging to transportation; luxury goods belonging to personal equipment, including high-end clothing, perfumes, leather bags, watches; leisure travel includes high-end luxury hotels, etc.; luxury goods in living, including expensive alcohol condiments, ingredients, etc. [5] In the macro economy, luxury goods belong to the product with the highest value/quality relationship ratio. Luxury goods originated in France in the 17th century at the earliest, and luxury winds were set off in the palace. Hedonism was the philosophy of life of the French nobility at that time, and luxury goods were born from now on. [6] To this day, luxury goods have become indispensable in French culture-and the French have so far attached great importance to the cultural benefits created by luxury goods for France. Since the research object of this article is college students with weaker consumption capacity, the luxury goods referred to in this article are more personal equipment luxury goods, including boxed shoes and clothing.

\subsubsection{Motivation}

The motivation is to promote-the inherently driven behavior of the individual to act and maintain the psychological motivation of the individual behavior and lead to a goal. The most essential difference between the need and the motivation is the need to refer to the original motivation and the motivation refers to the targeted goal, for example: thirst is different from buying water for thirst.[7] The motivation is generated based on the needs. The need is just a simple driving force, manifested as you want something or a kind of intention.

Once there is a goal appropriate to the need, the need as a potential driving force may be transformed into motivation. Therefore, the need is the basis of the motivation and the necessary 
condition for the motivation; the two factors of the motivation are the strength of need and the incentive goal.[8] The essence of consumer motivation is a kind of motivation." The inherent driving force that causes consumers to buy a certain product or labor service is called the purchase motivation"; the consumption motivation is divided into obvious motives and internal hidden motives, which include psychological and physiological two types, the implicit motivation includes macro and micro research.[9]

Scholars divide the types of consumer shopping motives into: types of truth seeking, new seeking, beauty seeking, asking for integrity, asking for convenience.[10]

\subsubsection{Consumer Behaviors}

Consumer behavior varies from person to person. However, there are general laws. Consumer behavior in a narrow sense: it only refers to consumer purchasing behavior and actual data of consumer consumptions. Broadly speaking: the various actions taken by consumers to obtain, use, dispose of consumer goods and the decision-making process that precedes and determines these actions, and even includes the acquisition of consumer income's complex processes, consumer behavior is dynamic, it involves the interaction between perception, cognition, behavior and environmental factors, and also designed the transaction process.[11]

In marketing, the decision-making process theory defines consumer behavior as the decisionmaking process for consumer purchase, consumption, and disposal. The theory of experience defines consumer behavior as the process of consumer experience. Often emotional consumers will consume and dispose of it in the experience. The stimulus response theory holds that consumer behavior is the consumer's response to stimulate; And studies consumer behavior from the relationship between consumers and stimuli. The balanced coordination theory holds that consumer behavior is an interactive behavior between consumers and marketers, and is the result of a balance between each side. [12]

\subsection{Literature Survey}

In the past 100 years since the 20th century, luxury goods dealers have not really paid attention to consumer behavior and inherent needs. However, the fashion trend of luxury goods industry is led by designers. Now the scale of the luxury goods industry is expanding, and competition will continue. At the same time, the demand of emerging consumers is diversified, and the luxury goods industry is developing as well. Jianqiu Wu (2014) believed that consumers, especially Chinese consumers, had a "face consciousness" in products and commerce. In marketing strategy, highlight the high quality and characteristics of luxury goods, choose star endorsements to recommend to consumers, and attract more consumers.[13] Veblen (1899) believed that luxury consumers bought luxury goods to show off to others that in order to obtain a higher social status and show off wealth, consumers would spend more money on luxury goods. Leibenstein (1950) developed Veblen's point of view and proposed the three motives of "show off from the crowd, uniqueness and luxury". The purpose of the audience was to obtain the recognition of external majority and recognition of several people reflected their social value in the group; the uniqueness was to distinguish themselves from others created your own value through differences and show off your wealth and social status to the outside world.[14] Hanqiong Fang (2009) believed that in the decision-making process of luxury consumption behavior, brand size, the routes of green health, communication channels and experience consumption were the four main factors that affect brand selection and consumption decision-making process.[15] Linyan Feng and Xinxin Wang (2015) believed that the key to successfully shaping a brand is to cultivate customer brand awareness, to give full play to subjective initiative, influencing consumer judgment and decision-making, and consumers in the process of consumer brand awareness, Luxury brand awareness is subjective, social and interactive. Therefore, from the perspective of constructionism, luxury branding had more practical significance.[16]

In summary, luxury goods had always existed as top consumer goods. It is the living synonym of people who pursue high-end life and enjoy life. In essence, luxury goods are like people's dream, in the process of dream realization that the release of craving emotions and changes in inner factors have 
made people keen on luxury goods consumption, even have the exaggerated consumption behavior of consuming with high prices. Luxury goods play an intermediary role in the process of people's consumption, and are affected by the inherent driving force carried by people's psychological factors, resulting in luxury consumption behavior.

The formers used the following models for consumer behavior research:

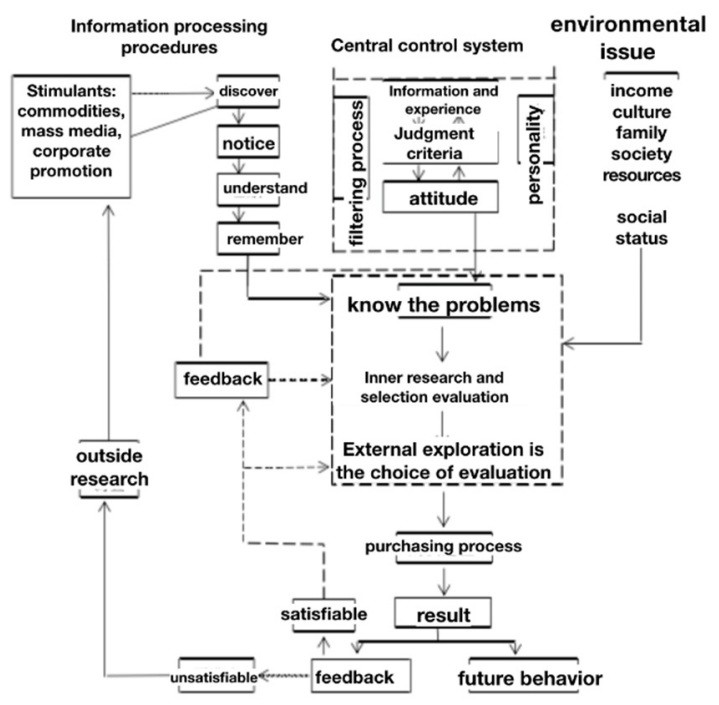

Figure 1. Engel-Kollat-Blackvell model

Engel-Kollat-Blackvell model: The EBK model, also known as Engel model, is a more complete and clear theory of consumer behavior currently. This model was proposed by Engel, Kollat and Blackwell in 1968 and amended in 1984. The focus is on analysis from the purchase decision process. [17] Engel model mainly shows that when people are stimulated by the outside world, they will form the potential memory of commodities and enter the next consumption. Consumer action constitutes the first impression. In addition to their own environment and consumer demand, there are past consumer experiences to find-some commodities that can meet your own needs. Under the influence of these factors, consumers make purchase decisions. after the consumer action is over, the consumer will evaluate the results, such as Figure 1.

S-O-R Model: The general model of human behavior is the s-o-r model, which is "stimulationpersonal physiology, psychology-reaction". Specifically, the psychological activities that people will experience between consumption stimulation and purchasing behavior are called consumer black boxes. The so-called black box is that this person cannot analyze its internal structure, only to analyze its composition principle from the side, or to open its internal structure, its composition principle will be damaged, so that more information cannot be obtained. [18] As the theme awareness increases, black boxes can also be converted into gray boxes or white boxes, that is, changes in people's psychological factors.

Xiaohui Zhu (2006)'s comparative analysis of the empirical study of Chinese consumer luxury consumption motivations. Due to cultural differences, consumers in the East and the West have different self-concepts, which have produced different consumption motivations. Luxury consumption motivation: [19] As shown in Figure 3. 


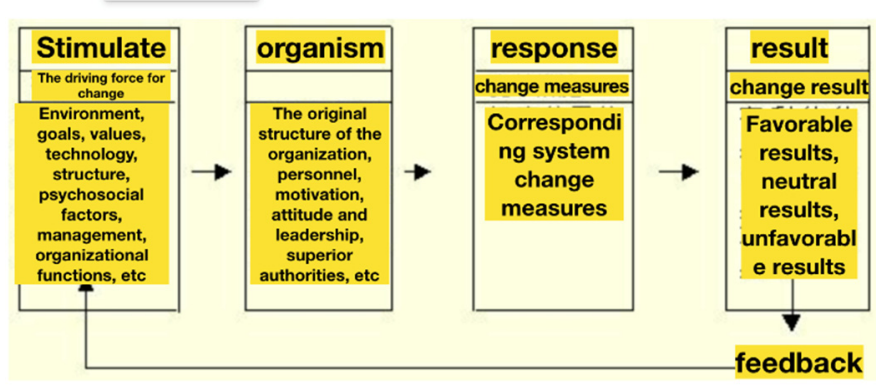

Figure 2. S-O-R Model

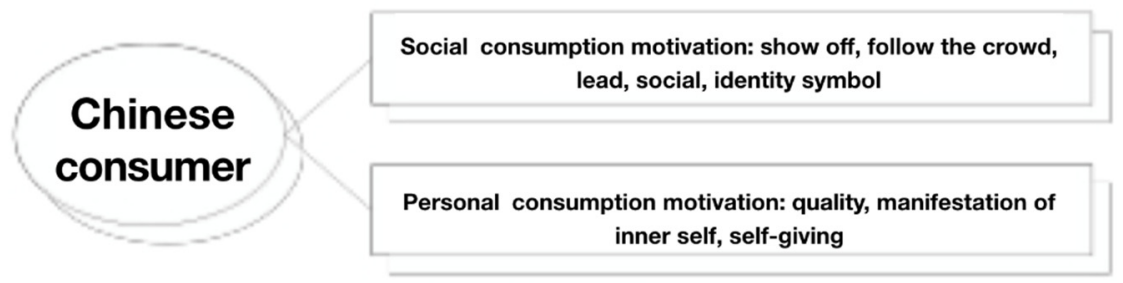

Figure 3. Luxury consumption motivation model of Chinese consumers

\subsection{Literature Commentary}

The literature review found that many scholars have conducted systematic research on the consumption of luxury goods in my country and have relatively rich results. They have found that the motivation of our residents to consume luxury goods has gradually changed from showing off their motives to socially oriented/self-value definition motives.

However, many scholars have conducted research and analysis on luxury consumption motives before, in the process, it was found that there are few investigations and studies on the behavior of young people or college students consuming luxury goods or college students' consumer behavior. In a limited survey of luxury consumption motivations for college students, this article also found that there is a lack of some research on the current consumption behavior and consumption psychology of college students. In the survey of young people's motivations for consuming luxury goods, it is possible to get the conclusions of college students' irrational behavior in excess rational behavior when consuming luxury goods, and college students' consumption of luxury goods in order to have a face or show off among their friends; This article has depth-research on the consumption of luxury goods by college students in order to find the motivation for college students to consume luxury goods.

\section{The Research Method}

The research method used in this article is quantitative analysis and questionnaire survey. Based on the epidemic situation, this questionnaire uses the method of distributing the recycling questionnaire online. The theme of the survey in this article is the motivation of college students to consume luxury goods. According to the literature review, the research variables and measurement methods were determined, and a questionnaire was developed. This questionnaire survey is mainly divided into 2 dimensions: 1. "Consumer factors": including age in demographic variables, source of income, and face awareness and group awareness in psychological characteristics. 2. Environmental factors include the impact of product value on consumers' motivation to purchase luxury goods, and the impact of marketing strategies on consumers' willingness to purchase and purchase behavior. 


\section{Analysis of Luxury Goods Consumed by College Students}

The main target of this survey is the motivation of consuming luxury goods by respondents-why they consume luxury goods and the impact of luxury goods on themselves, through attitude scales and single-choice\&multi-choice methods to allow consumers to objectively measure their selections. The purpose of the anonymous survey adopted in this study is to ensure the authenticity, objectivity, and completeness of the answer. The specific contents are as follows: (The following table answers statistical analysis of data for this questionnaire survey).

\begin{tabular}{|r|r|r|}
\hline 2. gender & \multicolumn{2}{|l|}{} \\
\hline & percentage & total \\
\hline 1 & $42.50 \%$ & 34 \\
\hline 2 & $57.50 \%$ & 46 \\
\hline $\begin{array}{c}\text { effective } \\
\text { response }\end{array}$ & & 80 \\
\hline
\end{tabular}

Figure 4. Gender attitudes towards luxury goods

As shown in Figure 4, gender is not different in attitudes towards the purchase of luxury goods. This reflects the dominant-consumer attitude of young groups, and is not significantly affected by gender.

As shown in Figure 5, the relationship between the disposable amount and the attitude of buying luxury goods, as well as the type of luxury goods purchased and the frequency of purchasing.

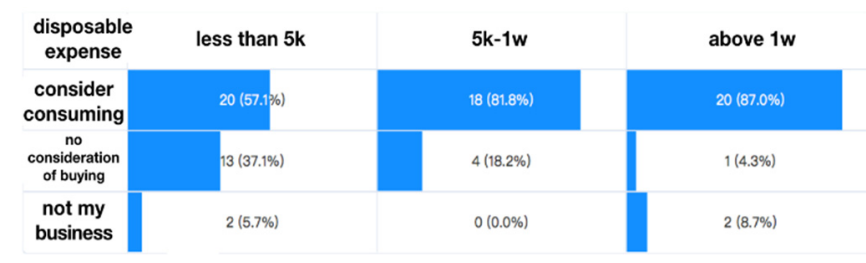

Figure 5. The relationship between the disposable amount and the attitude of buying luxury goods

According to the data, the disposable amount is proportional to the attitude of buying luxury goods. With the increase in quota, the frequency of purchasing luxury goods and the value of commodities will also increase accordingly. In summary, among young groups, the more money they can control, the more obvious the attitude of buying luxury goods and the frequency increases accordingly, vice versa.

Most college students buy luxury goods from their parents and a small number of people come from working, and most people buy luxury goods buy luxury goods once a year, so it is concluded on the side that the more cost of living for college students, the frequency of purchasing luxury goods will be relatively increasing.

It can be seen that for the majority of sampled college students, the main reason for buying luxury goods is good quality. They are more willing to spend more money to buy better quality commodities. Some students will use luxury goods as a reward for themselves. It is a benign relationship for college students; It is different comparing with the research by predecessors showed that college students consume. luxury goods are to show off.

\section{Summary of the Article}

\subsection{Discussion of the Data Conclusion}

This article studies the factors of affecting the luxury goods motives of college students through literature review and questionnaire survey, conducts an online anonymous questionnaire survey of 80 
college students, and establishes an impact model for luxury goods consumption motives through literature review "Grounded theory". The model proposes hypothetical influencing factors as questionnaire design questions, distributes questionnaires, recycles effective questionnaires, collects data, and conducts statistical analysis of the data to obtain the following conclusions:

Factors of affecting social and personal motives of luxury goods consumption and luxury goods consumption, gender motives do not have obvious relevance, nor do social motivations and dignity. Personal motivation is more relevant with product perception value. The causality between personal motivation and luxury goods is regarded as values and decent consciousness. The value of luxury products has a strong predictive effect on personal-oriented motivation.

The main sources of expenses for the consumption of luxury goods by college students are parents, loans, and part-time work, so according to the survey, the employment of young groups has not had a significant impact on the attitude of consuming luxury goods. The main factors affecting the motivation for consuming luxury goods are monthly disposable expenses and quality of the products.

For college student, marketing stimulus is not positively related to luxury goods consumption motivations. This is different from previous research results. The reason may be: the designed college student group is different (this article is mainly for international students), and the historical background is different, the thinking and the education received are different, and the social atmosphere is also different.

\subsection{Recommendations for Reasonable Purchase of Luxury Goods by Universities}

The group of college students refers to the group of people who are receiving higher education and have not yet entered the society. They are at the forefront of new social technologies and ideas; they have both Chines and western education, and their ideas are also different from many years before.

For college students, it is the period that their value and consumption values growing and changing. The mind and way for thinking is not yet mature, and they do not work so do not have money from themselves. (The economy comes from parents). Because of the people around them, they have a strong desire for consumption. For their own consumption motives, college students cannot grasp the virtual pursuit of social status, identity, face, etc., which may lead to the young group's most irrational consumption behavior in the purchase of luxury goods. According to the research in this article, consumer behavior refers to consumer purchasing behavior, and there are no standard answers for consumer behavior. This article is to give college students some positive recommendation. Based on the research results to guide the college students to moderate consumption, combined with their own adjustment, consume luxury goods appropriately.

The main reasons that affect college students' consumption of luxury goods are: face consciousness, product value, and influence of reference group.

For those college students:

Consumer values are formed from an early age, family education is very important, parents' consumer behavior will subtly affect young consumer groups; from an early age, the concept of "spending money on the blade" should be established, that is to say, teenagers need to know to spend money on what you need not everything you want. Parents can also start with the control of pocket money. According to the above study, it is found that the disposable amount has a great positive impact on the attitude and frequency of purchasing luxury goods, so reduce a little pocket money does not reduce parents' love for children. Instead, it is more important for them to know how to allocate their pocket money to both satisfy their needs and wants.

With the development of society, information-convenience has great effect on college students. As the media starts to spread with consumerism from media network platforms, young people should have their own judgement. Also, social media has responsibility to spread more positive concepts of consuming luxury goods.

For merchant merchants:

When marketing commodities, pr/spokesperson can use the star effect to help young people establish a sense of reasonable consumption. Young people receive different educational backgrounds, 
and most young groups accept luxury goods purchases. However, the economic source of some college student groups is from parents or loans, which means that the ability of consuming luxury goods is much greater than the economic ability of college students, so the luxury merchants can also develop sub-line for students or teenagers which focus more on leisure and fashion goods with lower prices. It will be more suitable for college students.

\subsection{Deficiency and Outlook}

Because of the COV-19, it will be more complicated to spread and collect samples. Hope to collect more samples in future to have more correct analysis.

\section{References}

[1] Analysis of the size of China's high net worth population in 11.08.2016.

[2] Analysis report on China's luxury industry in 2018 - Forecast of market operation situation and development trend.09.30.2018.

[3] information on: https://www.sohu.com/a/310426556_651625.

[4] Wolfgang ratzler, luxury brings wealth, CITIC press, 2003.

[5] information on: https://baike.baidu.com/item/ Luxury /1297?fr=aladdin.

[6] information on: http://www.chyxx.com/industry/201805/637919.html.

[7] information on: https://baike.baidu.com/item/ motivation /18293433?fr=aladdin.

[8] information on: https://baike.baidu.com/item/ Consumption motivation /5411128?fr=aladdin.

[9] information on: https://baike.baidu.com/item/ Consumer Behavior $/ 5370760$.

[10] information on: https://baike.baidu.com/item/ Consumer motivation /7015766?fr=aladdin.

[11] information on: https://baike.baidu.com/item/ Consumer Behavior /5370760.

[12] information on: https://wenku.baidu.com/view/04812dca65ce050877321370.html\#.

[13] Jianqiu. Wu. A comparative study of Chinese and American consumers' willingness to buy luxury goods [D]. Zhejiang University of science and technology,2014,12.

[14] Veblen T. The Theory of Leisure Class[M]. New York: Vanguard Press, 1899:57-59.

[15] Leibenstein, H. Bandwagon, Snob, and Veblen Effects in the Theory of Consumers' demand[J]. Quarterly Journal of Economics, 1950, 64(2): 183-207.

[16] Hanqiong Fang. A study on China's new luxury consumption behavior [D]. Fudan University,2009.

[17] Linyan Feng. The latest development and Enlightenment of luxury brand research at home and abroad [J]. Foreign economy and management,2015,01.

[18] information on: https://wenku.baidu.com/view/523b386b1eb91a37f1115c85.html.

[19] https://wenku.baidu.com/view/a8fd5d9f83c758f5f61 fb7360b4c2e3f572725cc.html.

[20] Xiaohui Zhu. An empirical study on luxury consumption motivation of Chinese consumers [J]. Business Economics and management,2006, 177(7): 42-48. 